\title{
The Americas region declares that rubella has been eliminated
}

Eurosurveillance editorial team (eurosurveillance@ecdc.europa.eu) ${ }^{1}$

1. European Centre for Disease Prevention and Control (ECDC), Stockholm, Sweden

Citation style for this article:

Eurosurveillance editorial team. The Americas region declares that rubella has been eliminated. Euro Surveill. 2015;20(18):pii=21120. Available online: http://www. eurosurveillance.org/ViewArticle.aspx?Articleld =21120

At a Pan American Health Organization/World Health Organization (PAHO/WHO) meeting in April 2015, an international expert committee declared that the Americas region is free of the endemic transmission of rubella [1]. Rubella and congenital rubella syndrome are the third and fourth vaccine-preventable diseases to be eliminated in the Americas, after smallpox (1971) and polio (1994).

The eradication of rubella follows a 15 -year initiative which involved widespread vaccination against measles, mumps and rubella (MMR) in the Western Hemisphere.

When contracted in early pregnancy, rubella can cause miscarriage or birth defects.

Read more here.

References

1. Pan American Health Organization/World Health Organization (PAHO/WHO). Americas region is declared the world's first to eliminate rubella. Washington: PAHO; 2015. Available from: http://www.paho.org/us/index. php?option=com_content\&view=article\&id=135\%3Aameric as-region-free-of-rubella\&Itemid=0\&lang $=e n$ 